\title{
Leadership in Perspective of the Organizational Frame
}

\author{
Huiling Jiang \\ Zhejiang Yuexiu University of Foreign Languages, Shaoxing, China \\ Email: 576828479@qq.com
}

How to cite this paper: Jiang, H.L. (2020) Leadership in Perspective of the Organizational Frame. Open Access Library Journal, 7: e7026.

https://doi.org/10.4236/oalib.1107026

Received: November 21, 2020

Accepted: December 7, 2020

Published: December 10, 2020

Copyright $\odot 2020$ by author(s) and Open Access Library Inc.

This work is licensed under the Creative Commons Attribution International License (CC BY 4.0).

http://creativecommons.org/licenses/by/4.0/

\begin{abstract}
This qualitative research is a case study focusing on leadership style and how leaders in School of Education Science, Nanjing Normal University (SES, $\mathrm{NNU}$ ), carry out their leadership. Interview method is used for the study with 5 questions, 1) What are your major responsibilities? 2) What do you look for when you observe subordinates? 3) What are some ways you provide to support for subordinates? 4) What would you say are the most pressing issues that you are deliberating on now? 5) How would you describe your leadership style? Respondents in this study are two leaders in SES, NNU. The theory of the organizational frame by Bolman and Deal (2008) is used to analyze the response and date I have collected. By study, I want to see, 1) How the leaders in SES, NNU make sense of their organization, 2) How they apply their leadership into practice leadership according to the character of their organizational situations, 3) What implication we can have to our practice? I find that two leaders understand SES and its staff. They carry out their leadership in perspective of structural frame mainly and show some skills for political frame and that of human resources as well. Their practice implies us that organization frame provides a foundation for leadership style. What's more, organizational analysis, tacit understanding of the organization, appropriate measures, harmonious relationship and positive role by leaders and subheads are important for effective and efficient leadership.
\end{abstract}

\section{Subject Areas}

Education

\section{Keywords}

Leadership, Higher Education Institution, Organization Frame, Staff 


\section{Introduction}

The word "leadership" has different definitions due to various perspectives. Some scholars regard leadership as a behavior guiding group activities to achieve common goals of an organization. Some take it as a process to influence or urge others to work hard in an effective way and then achieve organizational goals. Leadership is a common social phenomenon, existing in countries, regions, societies, organizations, groups and even families. Leadership theories are those studying the effectiveness of leadership activities. The core of the various studies on it includes determining the factors influencing the effectiveness of leadership, the methods and ways to improve the effectiveness of leadership, and improving the organizational variables that have something to do with leadership (such as organizational commitment, employees' willingness to stay and performance of subordinates). Traditional viewpoints went through 3 stages-Trait Theories (Kirkpatrick \& Locke 1991 [1]; Judge et al. 2002 [2]), Behavioral Theories (Lewin et al. 1939 [3]; Kahn \& Katz 1953 [4]; Bales 1954 [5]; Likert 1961 [6]; Blake 1964

[7]), Contingency Theories (Fiedler 1964 [8], 1971 [9], 1976 [10]; Hersey \& Blanchard 1969 [11], 1982 [12]). With new context and problems arising in management practice, researchers managed to explore new models and theories of leadership to explain the phenomenon of leadership from some new perspectives. Some of them even changed people's understanding of leadership research, among which Leadership-Member Exchange Theory (Jacobs 1970 [13]; Dansereau 1995 [14]; Graen \& Uhl-Bien 1995 [15]), Transformational Leadership Theory (Bass 1985 [16], 1994 [17]) and Charismatic Leadership Theory (House \& Howe II 1992 [18]; Conger \& Kanung 1987 [19]) caught our eyes. These theories have been utilized widely to different organizations and functioned in helping leaders seek an effective and efficient leadership. In practice, effective and efficient leadership plays a determinable role in the run of an organization. It has been an essential contributor for the growth of an organization. While it's kind of scarce, which results in the different institutional operations. Many practitioners devote their time and energy to apply leadership theory in different situations so that they can find an appropriate leadership style in different contexts. My case study is one of them.

\subsection{Purpose of the Research}

My case study focused on how leaders in the School of Education Science, Nanjing Normal University (SES, NNU), in the mainland of China achieved the effective and efficient leadership by making sense of their organization. NNU was chosen because it's one of 95 First-class Disciplinary Construction Universities in the mainland of China. Its School of Education Science is one of three most powerful subunits in terms of academic strength. The results from my study on it may be inspiring. Specifically, I wanted to reflect on the following questions:

- How do the leaders make sense of their organization?

- How do the leaders apply their leadership according to the character of their 
organizational situations?

- What is the implication to guide our actions, thus improving our efficiency and effectiveness as actors within the organization?

\subsection{Theoretical Framework}

Bolman and Deal (2008) describe the four frames manifested in different organizations-Structural Frame, Human Resources, Political Frame and Symbolic Frame. Their leadership theory has four essential frameworks: structural, human resource, political, and structural. The theory relates that the four frameworks or orientations signify the ways in which leaders view organizational situations, shape how these situations are defined, and describe how they can be managed effectively. The human resources and structural frames are related to the effectiveness of managers, while the political and symbolic frames relate to the effectiveness of leaders. Bolman and Deal describe the difference between a leader and a manager as "managers focus on execution, leaders on purpose" (Bolman and Deal 2008) [20]. Bolman and Deal also assert that leaders bearing leadership tendencies in each of the four frames will result in the most effective leadership style (Bolman and Deal 2008) [20].

The structural frame embodies efficiency, structure and policies. Leaders who are dominant in the structural frame value data and analysis, clearly set direction, hold stakeholders accountable, and restructure by problem-solving. The human resource frame focuses on the interaction between the needs of the organization and the individuals. Leaders dominant in the resources frame value relationships and emotions and lead via empowerment and facilitation. Leaders dominant the political frame emphasize conflict and competition among different interests for scarce resources. Leaders who are dominant in the political frame are networkers, coalition-builders, and negotiators. Leaders dominant in the symbolic frame place meaning and predictability in what is considered a disordered work and they are attentive to ceremony, ritual, and stories (Bolman and Deal 2008) [20].

Bearing the organizational frame in mind, effective leadership takes place if leaders can properly diagnose the development stage of subordinates in a specific situation and then exhibit the proper leadership style that matches the situation. Thus the leaders need to have the ability to make sense of the context, including the staff and the organization, the flexibility to apply the different styles of the leadership and the capacity to sense and improve the situation. Only with a view to both the organization situation and the development level of the staff, can leadership be efficient and effective.

\subsection{Methodology}

\subsubsection{Interview Method}

I designed 5 questions as follows, 1) What are your major responsibilities? 2) What do you look for when you observe subordinates? 3) What are some ways 
you provide to support for subordinates? 4) What would you say are the most pressing issues that you are deliberating on now? 5) How would you describe your leadership style? Focusing on the leadership of SES, I intentionally chose two leaders of the school as my interviewees (Mr. HU and Mr. GU) because then I was a doctoral degree candidate in SES, NNU and Mr. HU was my supervisor. When I went to my supervisor's office, I met Mr. GU several times and read his works, which made us have topic to talk when I met Mr. GU in corridor of teaching building. Thus it didn't take any trouble for me to make appointments with them. I interviewed them separately with the same questions. The questions guided them to provide me with the information about their understanding about organization and the leadership activities. Their responses were taken down as the written script for analysis, synthesis and tracing what was important in their applying leadership style. Besides, the information about SES on internet is of help for me to see the structure of the school I heard them mention the structure but he didn't explain it.

\subsubsection{Respondents}

Two leaders I have interviewed are supervisors of the doctoral degree candidates. One is Mr. HU, the dean of the school. His job is to determine the goal of the school, make strategic decisions on the basis of the consensus by all members in his leading team and take accountable for the resource management and financial issues. He has the final decision in the recruitment of the staff in the school and the making of the rules and regulations of the school. The other one is Mr. GU, the General Secretary of the School Committee of Communist Party of China (CPC). His job is to maintain and drive positive morale of the staff, to keep the stability and solidarity of the school and to make the publicity of the achievement of the school. For the interview, I phoned them, making an appointment with them respectively, and interviewed them in their offices.

\subsubsection{Brief introduction of Nanjing Normal University}

NNU has a long history. It can be traced back to Sanjiang Normal Institute established in 1902 by Zhang Zhidong, Governor-General of Qing Dynasty in charge of Jiangsu and Jiangxi. The other source of Nanjing Normal University is Huiwen Academy established in 1888. Now NNU is one of the key universities in Jiangsu Province and financed as ranked among list of First-class Disciplinary Construction University. Today's NNU contains 23 schools and 2 independent colleges, covers an area of 2,179,633 square meters among which 932,076 square meters are buildings. The staff population is over 3250. Among its 2103 academic personnel, 436 people are professors and 806 are associate professors. Now there are 1435 doctoral degree candidates, 10,293 bachelor degree candidates and 17,900 undergraduates, excluding that of the independent colleges. The library, with the total collection of paper documents of 3.8 million volumes and 148 electronic databases, occupies an area of 39,705 square meters. At present, Nanjing Normal University has been a comprehensive university assuming tasks 
of education and scientific research. The current university is composed of three campuses, "Suiyuan Campus", "Xianlin Campus" and "Zi Jinshan Campus". The former one is the main campus located in the northern part of Nanjing and enjoys the reputation as "one of the most beautiful campuses of the East" for its quaint buildings [21].

The School of Education Science (SES), a subunit of NNU, is located on both Suiyuan Campus and Xianlin Campus. SES has a long history, too. And now there are about 126 faculty staff assuming academic tasks, among which the number of professors and associate professors is 79. The school provides bachelor degree, master's degree, and doctoral degree as well.

\section{Presentation of the Response}

The interview provided me with the indication of how the leaders made sense of their organization and thus determined their leadership style and activities. In the course of interview, both of them focused on the rules and regulations, the structures, the staff and the working space.

In making the rules and regulations, each of the two leaders had their own priorities. Mr. HU obviously laid emphasis on both the letters and spirit of law, which can be seen when he talked about his responsibilities and how he supported the staff,

What I need to do is to maintain daily routines and proper working system and to inspire the staff s initiative as well. I achieve it by making rules and regulations to guarantee the staff s commitment to teaching and scientific research.

Besides, he stated his way to support the staff,

- To create a harmonious working place so that the staff can work with easement and pleasant mood.

- To help the staff overcome the difficulties they are encountered with in their daily life or routine work.

Mr. GU understood Mr. HU's support to the staff, and said,

Firstly, we trust them fully and inspire their initiative instead of constraining them. Secondly, we hold a series of activities to promote communication and understanding among the staff so that they can have a better working surroundings. Thirdly, we care about the affectional concern to the staff. We'll send our best regards on their birthday or wedding ceremony, or pay visits to them when one member is ill, or brings a baby to the world, etc. Fourthly, we guide the staff with a bright future. We let every one knows about our vision and the immediate goals.

Actually, both of the leaders bear humanization in mind. When Mr. HU talked about his current priorities, he said,

I $m$ considering how to contend for more office premises for the whole school so that the faculties and institutes can have more space to handle 
with affairs. And now the university is bringing about a new reform plan on the personnel system. I $m$ thinking about how to act in concert with it and minimize the negative impact on the staff $s$ mood to eliminate the staff $s$ doubt or uneasiness.

Mr. GU was dwelling on the two issues too. But obviously he has his own priorities due to the different responsibilities from Mr. HU's,

If we manage to get the additional office buildings, we'll allocate them to faculties and institutes. And now the university is bringing about a new reform plan on the personnel system. During the process of carrying out two issues, I need to know their reactions and enable individuals to express their opinions so that we can make the best decision, minimize the negative impact on the staff s mood or even eliminate the staff $s$ doubt or uneasiness.

When Mr. HU talked about his leadership style, he mentioned the structure of his school,

... we have different faculties and institutes in the charge of the experienced professors. They can facilitate further improvement in the run and make team members identify with the culture of the discipline as well as the school.

In supporting the faculties and institutes, he set the high standard and rigid procedures so that the staff recruited are excellent in the field of professions and demonstrate their willingness of collaboration. As Mr. HU stated,

What I care about is their scientific research capacity, professional ability and the capability of cooperating in the teamwork.

He shared the same focus as Mr. GU has when they are recruiting the staff, as the latter one said,

We'll have talks with the potential arrivals. During the course we can know his understanding to some specific issues, his way to deal with the relationship with others and the techniques to handle the problems. And we need to know the major experience at the critical stage of his growth so that we can analyze his ability to get around in the world, which is important as he works in a team.

Both of them cared about the professional skills and their ability to cooperate in the team, which guaranteed the quality of the staff. And they knew quite a lot about their organization. So Mr. HU thought, with the structure and the excellent staff, his style of leadership is the decentralizing approach, while Mr. GU is trying to focus on "keeping up the morale of the staff", the style of his leadership tended to be supportive.

\section{Analysis and Findings}

\subsection{Structure of SES}

When I heard Mr. HU mention the structure and staff of SES, "Structural Lea- 
dership" came to my mind. The reference to the information I got on the website about the school confirmed my thought.

The SES consists of the Educational Science Institutes and Educational Science Sub-Faculties. Both are made up of several teams in their lengthways, as Figure 1 presents. Each team is in the charge of the experienced scholars. The sub-divisions, though loosely coupled, provide members chances to exchange the tutoring experiences and have sustained the interaction with counterparts outside the university so that the scholars inside can be well informed of frontiers in their fields. Besides, the scholars in the institutes assume scientific research projects, independently or jointly. They are facilitated with respective administrative offices, which meant to provide the service for the academic personnel and the leaders.

In a word, the structure of SES is like a net, while the staff inside the net fulfil their obligations. One tutor may belong to different subdivisions at the same time according to the field she/he engages in. For example, she/he is a professional in preschool education. She/he then belongs to the Preschool Education Sub-Faculty. But meanwhile she/he belongs to the Institute of the Preschool Education as she/he does research in this field.

In its transverse construction, there are structures responsible for academic research, education and instruction for the full-time students for bachelor, master and doctoral degrees as well as for the part-time students pursuing adult education. The tutors may assume scientific research and provide the instruction for the students of different levels or different kinds. So the tutors take the accountability for the different tasks to the different leaders.

As the sub-faculty or the institute is made up of the peers at different stages of identical sub-discipline or field, it functions in mentoring the young fellows. The seasoned tutors make the new arrivals identify with the disciplinary culture as well as the institutional culture. The fruitful scholars exemplify the culture with the high commitment to teaching and research. So the structure in its lengthways is efficient in facilitating the development of young tutors and scholars in

Educational Science Sub-Faculties Educational Science Institutes

\begin{tabular}{|c|c|c|c|c|c|c|c|c|}
\hline 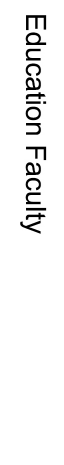 & 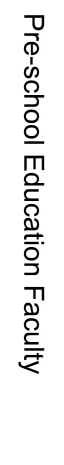 & 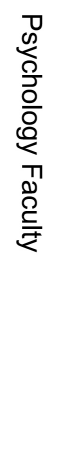 & $\stackrel{\text { m }}{\stackrel{9}{\circ}}$ & 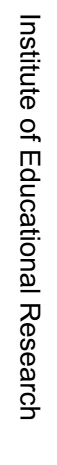 & 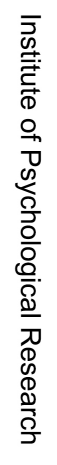 & 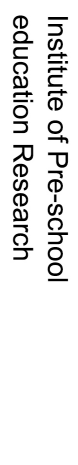 & 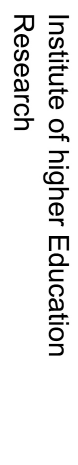 & 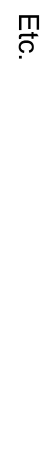 \\
\hline
\end{tabular}

Figure 1. Structure of SES in its Lengthways. Source: School of Education Science. General Introduction. http://jky.njnu.edu.cn/xygk/xyji1/jykxxy.htm, 2020 [22]. 
their respective fields. Meanwhile, the structure in its transverse is designed to ensure that individuals and units working together in the service of the school's goals. So the structure is well designed to fit the school's improvement as well as the staff's improvement. No wonder Mr. HU prefers the decentralizing approach. And though Mr. GU prefers the supportive approach. As SES is equipped with the well-designed structure and strict selected young members, his leadership style is the decentralizing one in its essence.

\subsection{Findings}

During the course of interview, I found both of the leaders shared common idea about the leadership activities and they illuminated me the parallelism (Andrews \& Crowther 2002) [23]. Firstly, Mr. HU and Mr. GU engaged in parallel work. They worked in the same direction with synergy instead of competition. The net effect was coherence between the school's espoused vision and tutors' preferred approaches to teaching functions and research obligations. The effect also contributed to a profitable and excellent working place. Mr. HU assumed major responsibility for strategic functions, including visioning, culture-building, consistence of school vision and practice, external alliance and communication, and resource management as well. Mr. GU maintained and even drove the morale of the staff, to unify the school and to make the publicity of the achievement in school. The ultimate goal was to provide a humanized working place for the staff so that they could achieve in their own fields. Secondly, the relationship between them was grounded in mutual trust. Both values the counterpart's potential leadership capacity fully and gave each other sufficient support in practice, which underpinned their position as leaders and their authority in making every effort for the improvement of the school. Thirdly, they valued individual expression. As they were considering allocating the office premises and making the school's personnel system, what they worried about was whether it would cause uneasiness. So I can infer that they would like to hear the different opinions from the staff so as to minimize the staff's worry. It seemed that the faculty was sometimes inconsistent with each other in the case of the interest. But actually their expression would be valuable for the profound decision making.

The organization of the SES was that of the Structural Frame, made up of faculties and institutes. It was fairly capacious for teaching and academic affairs (and now the leader is considering enlarging its office premises). The staff was highly competent with excellent professional skills and keen commitment to teaching and research. Traditionally, an academic organization was loosely coupled, the staff kept in touch with their peers inside or counterparts outside the school so that they could know the forefront of their own field. The leaders of the school trusted the staff. They managed to provide them with fine working space and facilities, and tried to provide them with the pleasant working atmosphere. The rules and regulations were made to guide the staff and coordinate their behaviors. The structure of this kind was of help for their academic growth 
so that they understood the necessity of the structure as well as the rules of the school. So the leadership of the School was the Structural Leadership. In fulfilling the school's teaching and research obligations and mentoring the young fellows, they followed the decentralizing approach. They were in pursuit of parallelism in carrying out their leadership, during which they functioned as a thermometer, a guider and a facilitator as well.

\section{Implication to the Leadership of Self-Practice}

\subsection{Understanding of My Organization}

My University is a private one founded in 1981 and was permitted to grant bachelor degrees by Ministry of Education in 2008. Now it has 14 colleges and schools, with 41 majors for undergraduates. More than $80 \%$ of its 1000 staff members are full-time teachers with master's and doctor's degrees, and $42 \%$ are full-time teachers with senior titles. Its two campuses, Jishan and Jinghu, cover an area of nearly $1300 \mathrm{Mu}$, among which are 420,000 square meters buildings. The library has more than 1.82 million paper books and 1.14 million e-books. According to the 2019 Discipline Ranks of China's Private Universities, it has been ranked No. 1 in literature program, No. 5 in Social Sciences, No. 9 in economics and No. 15 in management. Among its six disciplines, four are ranked in the list of top 20. My college, a subunit of the university, has 78 Chinese staff and 24 foreign ones. The organizational structure is similar with that of SES, NNU.

But actually two universities are different in terms of ownership which seems to be the root cause of differences in their academic capacity.

In the early 1980s, private higher education revived after nearly 30 years of suspension. It experienced hard situation at its revival in 1987, the Ministry of Education advocated "running education institutions with social forces" under the premise of "taking those by government as the principal part", which was carried out in practice in four aspects, 1) institutions of basic education and higher education are mainly run by the government. 2) In field of vocational and adult education, private institutions can be developed freely. 3) Regular schooling supported by government are given priority to rather than continuing non-schooling. 4) In field of compulsory education and non compulsory one, government gives priority to the former. In practice, China's original accommodation of higher education failed to meet the demands from mass with its rapid economic development after the reform and opening up, as there was a huge gap between demands and the admission caused by lack of national financial resources. The fact provided a chance for the revival of private higher education. But comparatively speaking, the proportion of private institutions in higher education and the percentage of students were apparently low. The private ones with low starting point and weak foundation were obviously inferior to public ones in terms of scale or quality. Inside institutions it turned out the capabilities of academics and administrative staff less satisfying, which was also demonstrated in my university. 


\subsection{Implication to the Leadership of Self-Practice}

Management Grid Theory (1964) emphasized the duality of leadership in that the leader's shows concerns for people or for tasks. Actually, his theory has been oversimplified as it neglects the different situations. Reddin (1967) [24] made the breakthrough with his 3-D management theory in that leadership can be positive as well as negative in some specific situations. Northhouse (2007) [25] used their theory to explain how the situational approach works. But Bolman and Deal broaden our vision to the leadership in that they made us know that the specific staff's development is at the micro-level. In our daily operation we need to know the organization as it is the working place they are in. we also need to take the staff's capacity and their professional development into consideration when we are determining our leadership style. And as the leaders of a college in a private higher education institution, we should know the peripheral organizations beyond the private ones and sense the broader peers.

The implications we can take from the leadership by the two leaders of SES, $\mathrm{NNU}$ is inspiring. When we want to ponder over the effective leadership activities as two leaders have achieved in SES, NNU, we should first take the context of my own university and the structure of my college into consideration so that we can determine the style of our leadership. Only with a better understanding of my organization, can we have a suitable leadership style and suitable measures. So the comparison between NNU and my organization is a premise for us to determine the our own leadership style. Though the organizational structure of my college is similar to that of SES, NNU, as a non-public higher education institution, my university has less resources in terms of finance and concern from government, which makes us have less chances to find satisfying faculty or capable heads for sub-divisions, thus makes my institution less developed in turn. We obviously lack the desired foundation on which structural leadership functions as two leaders have benefited from in SES, NNU. In terms of leadership, singling out one of the four styles that Bolman and Deal has raised is not enough. We may need integrate four when carrying out leadership activities in my college. Depending on the heads of sub-divisions, we need take priority on the needs of organizations and those of individuals as well. Therefore, we should not only set goals, provide policies and hold stakeholders accountable, but also use political skills to compete for more opportunities and resources from university authority so as to help progress of "managers" and academic personnel, improve their work efficiency and realize the effective development of the organization.

\section{Conclusions}

In terms of the leadership style of two leaders in SES, I would conclude that they showed the essence of structural leadership. I also saw the taste of that of human resource and political leadership by Bolman and Deal (2008) [20] and cultural leadership by Cheng (1994) [26]. Both of two leaders made sense of SES and the 
faculty before they determined their style of leadership, by which they took the constructive measures to improve the organization as well as the academic staff so they could have "easier" leaderships. They were keenly devoted to instruction and scientific research tasks as the scholars in their own fields, exemplifying the valued culture of the school enlightening the staff to identify with the culture of the school with mentoring by tenured professors. What counted was that two leaders depended on sub-division leaders to push the staff for excellence and ensured their performance with the values, standards and procedures established by NNU and SES as well. During the process, they also utilized the political approach to compete for the resources for staff, took in different opinions from staff in developing personnel policy. They functioned as a thermometer, a guider and a facilitator to guarantee the efficiency and effectiveness of their leadership in SES. They based on the context of SES and its staff so they managed effective and efficient leadership.

What the case study has implied me is not that their leadership is superior to the other three raised by Bolman and Deal (2008) [20], but that they have adopted appropriate one with combination of other styles after diagnosing their organization. As a leader of a college in a private university, we should bear the organizational structure and development stage in mind and prioritize the development needs, taking constructive measures.

\section{Conflicts of Interest}

The author declares no conflicts of interest regarding the publication of this paper.

\section{References}

[1] Kirkpatrick, S.A. and Locke, E.A. (1991) Leadership: Do Traits Matter? The Academy of Management Executive, 5, 48-60. https://doi.org/10.5465/ame.1991.4274679

[2] Judge, T.A., Bono, J.E., Ilies, R. and Gerhardt, M.W. (2002) Personality and Leadership: A Qualitative and Quantitative Review. Journal of Applied Psychology, 87, 765-780. https://doi.org/10.1037/0021-9010.87.4.765

[3] Lewin, K., Lippitt, R. and White, R.K. (1939) Patterns of Aggressive Behavior in Experimentally Created "Social Climates". The Journal of Social Psychology, 10, 269-299. https://doi.org/10.1080/00224545.1939.9713366

[4] Kahn, R.L. and Katz, D. (1953) Leadership Practices in Relation to Productivity and Morale. In: Cartwright, D. and Zander, A., Eds., Group Dynamics, Harper \& Row, New York.

[5] Bales, R.F. (1954) In Conference. Harvard Business Review, 32, 44-50.

[6] Likert, R. (1961) New Patterns of Management. McGraw-Hill, New York.

[7] Blake, R.R. and Mouton, J.S. (1964) The Managerial Grid. Gulf, Houston.

[8] Fiedler, F.E. (1964) A Contingency Model of Leadership Effectiveness. Advances in Experimental Social Psychology, 1, 149-190. https://doi.org/10.1016/S0065-2601(08)60051-9

[9] Fiedler, F.E. (1971) Validation and Extension of the Contingency Model of Leader- 
ship Effectiveness: A Review of Empirical Findings. Psychological Bulletin, 76, 128-148. https://doi.org/10.1037/h0031454

[10] Fiedler, F.E. (1976) The Leadership Game: Matching the Man to the Situation. Organizational Dynamics, 4, 6-16. https://doi.org/10.1016/0090-2616(76)90032-2

[11] Hersey, P. and Blanchard, K.H. (1969) Life Cycle Theory of Leadership. Training and Development Journal, 23, 26-34.

[12] Hersey, P. and Blanchard, K.H. (1982) Management of Organizational behavior: Utilizing Human Resources. Prentice-Hall, Englewood Cliffs.

[13] Jacobs, T.O. (1970) Leadership and Exchange in Formal Organizations. Human Resources Research Organization, Alexandria.

[14] Dansereau, F. (1995) A Dyadic Approach to Leadership: Creating and Nurturing This Approach under Fire. The Leadership Quarterly, 6, 479-490. https://doi.org/10.1016/1048-9843(95)90022-5

[15] Graen, G.B. and Uhl-Bien, M. (1995) Relationship-Based Approach to Leadership: Development of Leader-Member Exchange (LMX) Theory of Leadership over 25 Years: Applying a Multi-Level Multi-Domain Perspective. The Leadership Quarterly, 6, 219-247. https://doi.org/10.1016/1048-9843(95)90036-5

[16] Bass, B.M. (1985) Leadership and Performance beyond Expectations. Free Press, New York.

[17] Bass, B.M. and Avolio, B.J. (1994) Improving Organizational Effectiveness through Transformational Leadership. Sage, California.

[18] House, R. and Howell, J. (1992) Personality and Charismatic Leadership. The Leadership Quarterly, 3, 81-108. https://doi.org/10.1016/1048-9843(92)90028-E

[19] Conger, J.A. and Kanungo, R.N. (1987) Toward a Behavioral Theory of Charismatic Leadership in Organizational Settings. Academy of Management Review, 12, 637-647. https://doi.org/10.5465/amr.1987.4306715

[20] Bolman, L.G. and Deal, T.E. (2008). Reframing Organizations: Artistry, Choice, and Leadership. Jossey-Bass, San Francisco.

[21] Nanjing Normal University (2020) General Introduction. http://www.nnu.edu.cn/xxgk/xxjj.htm

[22] School of Education Science of Nanjing Normal University (2020) General Introduction. http://jky.njnu.edu.cn/xygk/xyji1/jykxxy.htm

[23] Andrews, D. and Crowther, F. (2002) Parallel Leadership: A Clue to the Contents of the "Black Box" of School Reform. International Journal of Educational Management, 16, 152-159. https://doi.org/10.1108/09513540210432128

[24] Reddin, W.J. (1967) The 3-D Management Style Theory. Training and Development Journal, 21, 8-17.

[25] Northouse, P.G. (2007) Leadership, Theory and Practice. 4th Edition, Sage Publications, Thousand Oaks.

[26] Cheng, Y.C. (1994) Principle's Leadership as a Critical Indicator of School Performance: Evidence from Multi-levels of Primary Schools. School Effectiveness and School Improvement, 5, 299-317. https://doi.org/10.1080/0924345940050306 


\section{Appendix. Interview Record}

\section{Interview with Mr. HU}

I: What are your major responsibilities?

A: What I need to do is to maintain the regular teaching order, normal working system and to inspirit the staff's initiatives as well.

I: What do you look for when you observe employees?

A: What I care about is their scientific research capacity, professional ability and the capability of cooperating in the teamwork.

I: What are some ways you provide support for employees?

A: To create a harmonious working place so that the staff can work with easement and pleasant. To help the staff overcome the difficulties they are encountered with in their daily life and routine work.

I: What would you say are the most pressing issues that you are deliberating on now?

A: I'm considering how to contend for the more office premises for the whole school so that the faculties and institutes can have more capacious space to handle the affairs. And now the university is bringing about a new reforming plan on the personnel system. I'm thinking about how to act in concert with it and minimize the negative impact on the staff's mood to eliminate the staff's doubt and uneasiness.

I: How would you describe your leadership style?

A: I think the leadership is by decentralizing approach. As we recruit the new staff with strict academic eligibility so once they can be admitted by the school, they have the makings of fine teachers. Besides, we have different faculty and institutes charged by the experienced professors, they can facilitate the new arrivals' improvement in the practice and make them identify with the culture of the discipline as well as the school.

\section{Interview with Mr. GU}

I: What are your major responsibilities?

B: to keep up the morale of the staff, to make the publicity of the school's achievement, to participate in the decision making of the school's development.

I: What do you look for when you observe employees?

B: the moral standing, working experience and the professional skills.

We'll have talks with the new arrivals. During the course we can know his understanding to some specific issues, his way to deal with the relationship with others and the way to handle the problems. And we need to know the major experience at the critical stage of his growth so that we can analyze his ability to get around in the world, which is important as he works in a team.

I: What are some ways you provide support for employees?

B: Firstly, we trust them fully and inspire their initiative instead of constraining them.

Secondly, we hold a series of activities to promote the communication and 
understanding among the staff so that they can have a better working surroundings.

Thirdly, we care about the affectional concern to the staff. We'll send our best regards to their birthday, or wedding ceremony with the aborative gifts, or pay visits to them once one of the staff is ill, or bring a baby to the world.

Fourthly, we guide the staff with the bright future. We let everyone knows about our vision and the immediate goals.

I: What would you say are the most pressing issues that you are deliberating on now?

B: If we manage to get the additional office buildings, we'll allocate to the faculties and institutes. And now the university is bringing about a new reforming plan on the personnel system. During the process of two issues, I need to know their reactions and express their opinions on behalf of them so that we can make the profound decision, minimize the negative impact on the staff's mood or even eliminate the staff's doubt and uneasiness.

I: How would you describe your leadership style?

B: I'd prefer the supportive behavior. And we have corresponding structure for the development of the staff's professional skills. What's more, the staff in our school has the high commitment, so I think the decentralizing style can be described to my leadership. 